\title{
Fatores associados à evasão de discentes de um curso de Terapia Ocupacional
}

\author{
Factors associated with students evasion of an Occupational Therapy \\ bachelhor degree
}

\author{
Brunna Emannuelly Nóbrega da Silva ${ }^{1}$, Marília Meyer Bregalda²
}

http://dx.doi.org/10.11606/issn.2238-6149.v29i2p111-119

Silva BEN, Bregalda MM. Fatores associados à evasão de discentes de um curso de Terapia Ocupacional. Rev Ter Ocup Univ São Paulo. 2018 maio-ago.;29(2):110-8.

RESUMO: A evasão estudantil é o desligamento permanente do discente do seu curso de origem antes de concluí-lo e se trata de um fenômeno multifatorial, pois pode estar associada a fatores pessoais e a fatores internos e externos à instituição. Essa pesquisa objetivou identificar e compreender os fatores associados à evasão do curso de Terapia Ocupacional da Universidade Federal da Paraíba. Aplicou-se um questionário semiestruturado com os discentes evadidos que aceitaram participar da pesquisa. Os dados das respostas às questões fechadas forneceram um panorama geral dessa evasão, e as respostas às questões abertas foram sistematizadas em categorias referentes aos posicionamentos dos discentes sobre o fenômeno. Verificou-se a multifatorialidade da evasão do curso, com predominância dos fatores pessoais, sendo a falta de identificação com o curso, o interesse por outra profissão e o desconhecimento sobre o curso os fatores mais apontados, seguidos pelos auxílios estudantis insatisfatórios. Desta forma, deve-se priorizar o investimento no conhecimento da profissão pela sociedade, no acompanhamento vocacional antes e depois do ingresso na universidade e desenvolver ações de luta pela melhoria da estrutura e do funcionamento do curso e da instituição e das condições de assistência e permanência estudantil.

Descritores: Evasão escolar; Educação superior; Terapia ocupacional; Estudantes.
Silva BEN, Bregalda MM. Factors associated with students evasion of an Occupational Therapy bachelhor degree. Rev Ter Ocup Univ São Paulo. 2018 May-Aug.;29(2):110-8.

\begin{abstract}
Student evasion is the permanent disconnection of the student from his or her course of origin before concluding it and it is a multifactorial phenomenon, since it can be associated with personal factors, and internal and external factors of the institution. This research aimed to identify and understand the factors associated with the avoidance of the Occupational Therapy bachelor degree of the Federal University of Paraíba. A semi-structured questionnaire was applied with the evading students who accepted to participate in the research. The data from the answers to the closed questions provided an overview of this evasion, and the answers to the open questions were systematized in categories referring to the students' positions on the phenomenon. The multifactoriality of the course avoidance was verified, with predominance of personal factors, being the lack of identification with the course, the interest for another career, and the lack of knowledge about the course are the most pointed factors, followed by the unsatisfactory student aid. Thus, priority should be given to investing in the knowledge of the career by society, in the vocational accompaniment before and after joining the university, and to develop actions to improve the structure and function of the course and institution, and conditions of care and permanence of the student.
\end{abstract}

Keywords: Student dropouts; Education, higher; Occupational therapy; Students.

Este artigo é resultado do Trabalho de Conclusão do Curso de Terapia Ocupacional da aluna Brunna Emannuelly Nóbrega da Silva ${ }^{1}$, sob orientação de Marília Meyer Bregalda ${ }^{2}$, docente do Curso de Terapia Ocupacional da Universidade Federal da Paraíba, João Pessoa, PB, Brasil. Endereço para correspondência: Departamento de Terapia Ocupacional, Centro de Ciências da Saúde, Universidade Federal da Paraíba - Campus I. Cidade Universitária. João Pessoa, PB, Brasil. CEP: 58051-900. E-mail: brunnaenobrega@gmail.com. 


\section{INTRODUÇÃO}

Cutende-se por evasão estudantil a saída
permanente de um estudante de seu curso de origem, sem tê-lo concluído ${ }^{1}$. Esse crescente fenômeno gera desperdícios sociais, acadêmicos e econômicos e se constitui como um problema que impacta diretamente os sistemas educacionais. Segundo o Instituto Nacional de Estudos e Pesquisas Educacionais Anísio Teixeira, além de acarretar desperdício financeiro, visto que a instituição educacional passa a se dedicar a um número inferior de estudantes em relação ao que estava preparada, a evasão estudantil se apresenta como indicativo de lacunas no processo de ensino e de ineficiência dos serviços prestados ${ }^{2,3}$.

A Secretaria de Educação Superior do Ministério da Educação relaciona a evasão estudantil a três principais conjuntos de fatores: fatores referentes a características individuais como personalidade, frustração com os cursos escolhidos, desinformação acerca do curso no momento de escolha e habilidade de estudo; fatores internos às instituições, relacionados a questões acadêmicas como falta de formação pedagógica ou desinteresse do docente, rigidez e desatualização curricular, escassez de estruturas de apoio como laboratórios de ensino e informática; e fatores externos às instituições, relativos à situação da profissão no mercado de trabalho e a conjunturas econômicas ${ }^{1}$.

Dados do MEC/INEP (2015) revelam que, no ano de 2010, o índice de acadêmicos de instituições de ensino superior que evadiram do curso para o qual foram admitidos era de $11,4 \%$ e, no ano de 2014 , esse número atingiu $49 \%$, totalizando um aumento de $37,6 \%$ em 4 anos. Nos anos de 2014 e 2015, os cursos da área de saúde apresentaram um índice de evasão estudantil de $20 \%$. Entre as 22 áreas elencadas, a da Saúde apresenta o décimo primeiro maior índice de evasão, juntamente com as Ciências Sociais e Comportamentais ${ }^{4,5}$.

No que se refere à Terapia Ocupacional, um estudo realizado em 2014 pelo Fórum Nacional de Pró-Reitores de Planejamento e de Administração das Instituições Federais de Ensino Superior (FORPLAD) apresentou dados de evasão dos cursos oferecidos em algumas universidades públicas, tais como UNB (13\%), UNIFESP (13,3\%), UFMG (10,6\%), UFRJ (11.6\%), UFPR (10.6\%) e UFSCar (7.4\%). Tais dados indicam que, no geral, os cursos de Terapia Ocupacional têm apresentado taxas abaixo da média de evasão dos cursos da área da saúde ${ }^{6,7}$.

Em relação ao curso de Terapia Ocupacional da UFPB, foco do presente estudo, desde o seu início, no ano de 2010, até fevereiro de 2018, o número de ingressantes foi de 488 discentes. Destes, 133 evadiram, o que corresponde a $27,25 \%$ do total de ingressantes.

Este trabalho teve como objetivos identificar e compreender possíveis fatores pessoais, internos e externos à instituição associados à evasão de discentes do curso de Terapia Ocupacional da Universidade Federal da Paraíba, e levantar possíveis estratégias de redução da evasão, a partir da ótica dos discentes evadidos.

\section{PROCEDIMENTOS METODOLÓGICOS}

O presente estudo é de natureza qualitativa, pois se dedicou a analisar aspectos processuais da evasão de discentes do curso de Terapia Ocupacional da UFPB, a partir dos pontos de vista dos discentes evadidos, trabalhando os diversos significados que permearam os dados e baseando-se na compreensão do fenômeno integrado ao seu contexto ${ }^{7,8}$

No mês de fevereiro de 2018, a Superintendência de Tecnologia da Informação (STI) da universidade disponibilizou os dados referentes à evasão do curso, em que constavam os nomes completos, e-mails e telefones dos discentes evadidos, que estavam categorizados em: evadidos por abandono, cancelamento de matrícula pelo discente e cancelamento de matrícula pelo sistema. Selecionaram-se para a pesquisa os discentes evadidos por abandono e os que cancelaram sua matrícula, tendo sido excluídos os discentes que tiveram suas matrículas canceladas pelo sistema e que por algum motivo não chegaram a iniciar o curso de Terapia Ocupacional na UFPB.

A coleta de dados foi realizada com a aplicação de um questionário semiestruturado, elaborado pela proponente do estudo, composto por 22 questões abertas e fechadas, 8 delas com subdivisões. Treze questões abordavam dados socioeconômicos dos participantes e as demais se referiam aos períodos de ingresso e abandono no/do curso, ao exercício de atividades de trabalho durante a permanência no curso, aos fatores que levaram à evasão, aos auxílios procurados e sua percepção sobre eles, a possíveis ações que poderiam tê-los feito permanecer no curso e ao retorno ao trabalho e/ou aos estudos após a evasão. O convite para colaboração com a pesquisa foi enviado aos discentes evadidos via e-mail e, após o aceite de participação, foram encaminhados, pelo mesmo meio, o Termo de Consentimento Livre e Esclarecido (TCLE) e o link para o questionário, a partir de um formulário eletrônico. Devido à baixa adesão dos evadidos à pesquisa, foram realizados contatos telefônicos e por meio de redes sociais e aplicativos de comunicação, acessados a partir de seus nomes e números de telefone. Os questionários foram respondidos durante os meses de março e abril de 2018.

A proposta de trabalho foi submetida ao Comitê de 
Ética em Pesquisa (CEP) do Centro de Ciências da Saúde da UFPB, de acordo com a Resolução 466/12 do Conselho Nacional de Saúde, referente a pesquisas com seres humanos. A participação na pesquisa foi antecipadamente apresentada e consentida através do TCLE, assegurando ao participante o sigilo das informações por ele concedidas e o direito de se retirar da pesquisa a qualquer momento, sem que isto lhe acarretasse nenhum dano'.

Foram incluídos como participantes do estudo os discentes evadidos do curso de Terapia Ocupacional da UFPB desde o seu início, no ano de 2010, até fevereiro de 2018, e que concordaram em participar da pesquisa. Foram excluídos discentes que possuíam matrícula ativa no curso; que fizeram a matrícula inicial, porém nunca chegaram a cursar; que realizaram trancamento, mas retornaram ao curso; e evadidos que se recusaram a participar da pesquisa.

Os dados provenientes das respostas às questões fechadas do questionário foram organizados em tabelas e gráficos, fornecendo um panorama geral das características socioeconômicas dos discentes evadidos e de aspectos específicos da evasão desses discentes. Com relação aos dados oriundos das respostas às questões abertas, os relatos dos participantes sobre ideias, opiniões e posicionamentos sobre a evasão passaram por análise de conteúdo e foram sistematizados em três categorias definidas previamente: evasão associada a fatores pessoais; evasão associada a fatores internos à instituição; evasão associada a fatores externos à instituição; soluções e estratégias para redução da evasão. Realizaram-se a leitura e a organização do material, norteadas pelos objetivos da pesquisa, de modo a definir e sistematizar categorias, para posterior tratamento dos dados ${ }^{10}$.

Os participantes que responderam estão identificados nos relatos pela letra $\mathrm{P}$, seguida do número correspondente à ordem de sua participação na pesquisa.

\section{RESULTADOS E DISCUSSÃO}

\section{Caracterização socioeconômica dos discentes evadidos do curso de Terapia Ocupacional da UFPB}

Dos 133 discentes evadidos, 46 responderam o questionário, totalizando $34,5 \%$ de colaboradores. Destes, $82,6 \%$ são mulheres e $17,4 \%$ homens; $41,4 \%$ se autodeclaram pardos, $34,8 \%$ brancos, $15,2 \%$ pretos, $4,3 \%$ amarelos e outros $4,3 \%$ não quiseram declarar. Com relação ao local em que viviam antes do ingresso no curso, $69,5 \%$ já residiam no município de João Pessoa, 15,3\% vieram do interior da Paraíba e, 15,2\%, de outros estados, como Pernambuco, Rio Grande do Norte e Rio Grande do Sul. A idade dos discentes evadidos varia de 17 a 55 anos, e 91,3\% estão na faixa etária de 20 a 40 anos, caracterizando-se, desta forma, como adultos jovens ${ }^{11}$.

Tabela 1 - Caracterização dos discentes evadidos do curso de Terapia Ocupacional da UFPB

\begin{tabular}{|c|c|c|}
\hline VARIÁVEIS & $N=46$ & $\%$ \\
\hline \multicolumn{3}{|l|}{ Sexo } \\
\hline Masculino & 08 & $17,4 \%$ \\
\hline Feminino & 38 & $82,6 \%$ \\
\hline \multicolumn{3}{|l|}{$\begin{array}{l}\text { Local de residência antes } \\
\text { do curso }\end{array}$} \\
\hline João Pessoa & 32 & $69,6 \%$ \\
\hline Outra cidade da Paraíba & 07 & $15,2 \%$ \\
\hline Outro estado & 07 & $15,2 \%$ \\
\hline \multicolumn{3}{|l|}{ Cor/Raça } \\
\hline Parda & 19 & $41,4 \%$ \\
\hline Branca & 16 & $34,8 \%$ \\
\hline Preta & 07 & $15,2 \%$ \\
\hline Amarela & 02 & $4,3 \%$ \\
\hline Indígena & 0 & $0 \%$ \\
\hline Não quis declarar & 02 & $4,3 \%$ \\
\hline \multicolumn{3}{|l|}{ Idade } \\
\hline 17-19 anos & 03 & $6,5 \%$ \\
\hline $20-25$ anos & 24 & $52,2 \%$ \\
\hline 26-31 anos & 09 & $19,6 \%$ \\
\hline 32-37 anos & 08 & $17,3 \%$ \\
\hline $38-43$ anos & 01 & $2,2 \%$ \\
\hline 44-49 anos & 0 & $0 \%$ \\
\hline $50-55$ anos & 01 & $2,2 \%$ \\
\hline \multicolumn{3}{|l|}{ Estado Civil } \\
\hline Solteiro(a) & 41 & $89,1 \%$ \\
\hline Casado(a) & 04 & $8,7 \%$ \\
\hline Divorciado(a) & 01 & $2,2 \%$ \\
\hline \multicolumn{3}{|l|}{ Filhos } \\
\hline Não tem. & 40 & $87 \%$ \\
\hline 1 filho & 02 & $4,3 \%$ \\
\hline$\geq 2$ filhos. & 04 & $8,7 \%$ \\
\hline
\end{tabular}

FONTE: Elaboração própria, 2018. 
Dentre os participantes, $52,2 \%$ cursaram o ensino médio em escolas públicas, $39,1 \%$ em particulares, e $8,7 \%$ o fizeram parte em escolas públicas, parte em particulares. Seus pais e mães apresentam graus diversificados de escolaridade: enquanto $32,6 \%$ das mães completaram o ensino superior, outros $28,3 \%$ delas não possuem o ensino médio completo; com relação aos pais, $28,3 \%$ concluíram o ensino superior e $39,1 \%$ não terminaram o ensino médio.

No que diz respeito à renda familiar, $43,4 \%$ dos respondentes afirmam ter uma renda de 1 a 3 salários mínimos, e 37\%, de 4 a 6 salários mínimos, o que localiza a maioria da população estudada nas camadas populares, que correspondem à chamada classe $\mathrm{C}$, cuja renda se encontra na faixa de $\mathrm{R} \$ 2.005,00$ a $\mathrm{R} \$ 8.640,00^{12,13}$.

A predominância de estudantes de camadas populares na amostra pode ser explicada pelo que alguns teóricos chamam de promessa de democratização do ensino superior brasileiro, que tem como uma das causas a implantação do REUNI (Reestruturação e Expansão das Universidades Federais) instituído em 2007, a partir do qual pessoas dessas camadas adquiriram a possibilidade de entrada e permanência no ensino superior. Entre as ações desse programa estão o aumento de vagas nos cursos de graduação, a ampliação da oferta de cursos noturnos, a promoção de inovações pedagógicas e o combate à evasão, que contribuem para a redução da desigualdade social no país ${ }^{14,15}$.

O Sistema de Seleção Unificada (SISU) também tem papel fundamental no processo de democratização do acesso ao ensino superior público e se constitui como um método de seleção em escala nacional que ocorre através da realização do Exame Nacional do Ensino Médio (ENEM) e visa destinar candidatos para vagas em cursos ofertados na rede federal de ensino superior pública. Anteriormente ao SISU, o ingresso em instituições de ensino superior federais se dava através de vestibulares próprios de cada instituição, o que dificultava o processo de inserção das camadas populares, devido, entre outros fatores, ao gasto com deslocamentos de estudantes que optavam por instituições de ensino superior mais distantes ${ }^{16}$.

\section{Fatores de evasão do curso de Terapia Ocupacional da UFPB}

Verificou-se que no primeiro período do curso houve o maior índice de evasão (50\%) entre os discentes participantes da pesquisa, seguido pelo terceiro $(20 \%)$ e segundo períodos (13\%). Desta forma, $89 \%$ da evasão concentra-se nos quatro primeiros semestres, ou seja, na primeira metade do curso, e somente $11 \%$ deixaram o curso do quinto período em diante e/ou não souberam informar.

Tabela 2 - Perfil socioeconômico de discentes.

\begin{tabular}{|c|c|c|}
\hline VARIÁVEIS & $N=46$ & $\%$ \\
\hline \multicolumn{3}{|l|}{ Cursou ensino fundamental } \\
\hline Escola pública & 22 & $47,9 \%$ \\
\hline Escola privada & 18 & $39,1 \%$ \\
\hline $\begin{array}{l}\text { Parte em escola pública e parte em } \\
\text { privada }\end{array}$ & 06 & $13 \%$ \\
\hline \multicolumn{3}{|l|}{ Cursou ensino médio } \\
\hline Escola pública & 24 & $52,2 \%$ \\
\hline Escola privada & 18 & $39,1 \%$ \\
\hline $\begin{array}{l}\text { Parte em escola pública e parte em } \\
\text { privada. }\end{array}$ & 04 & $8,7 \%$ \\
\hline \multicolumn{3}{|l|}{ Escolaridade do pai } \\
\hline Sem escolaridade & 0 & $0 \%$ \\
\hline Ensino fundamental incompleto & 13 & $28,3 \%$ \\
\hline Ensino fundamental completo & 03 & $6,5 \%$ \\
\hline Ensino médio incompleto & 02 & $4,3 \%$ \\
\hline Ensino médio completo & 08 & $17,4 \%$ \\
\hline Ensino superior incompleto & 07 & $15,2 \%$ \\
\hline Ensino superior completo & 13 & $28,3 \%$ \\
\hline \multicolumn{3}{|l|}{ Escolaridade da mãe } \\
\hline Sem escolaridade & 01 & $2,2 \%$ \\
\hline Ensino fundamental incompleto & 09 & $19,6 \%$ \\
\hline Ensino fundamental completo & 02 & 4,3 \\
\hline Ensino médio incompleto & 01 & 2,2 \\
\hline Ensino médio completo & 11 & $23,9 \%$ \\
\hline Ensino superior incompleto & 07 & $15,2 \%$ \\
\hline Ensino superior completo & 15 & $32,6 \%$ \\
\hline \multicolumn{3}{|l|}{ Renda familiar } \\
\hline Até 1 salário mínimo & 06 & $13 \%$ \\
\hline 1-3 salários mínimos & 14 & $30,4 \%$ \\
\hline 4-6 salários mínimos & 17 & $37 \%$ \\
\hline$\geq 6$ salários mínimos & 09 & $19,6 \%$ \\
\hline
\end{tabular}

FONTE: Elaboração própria, 2018. 
Gráfico 1 - Período de saída de discentes do curso.

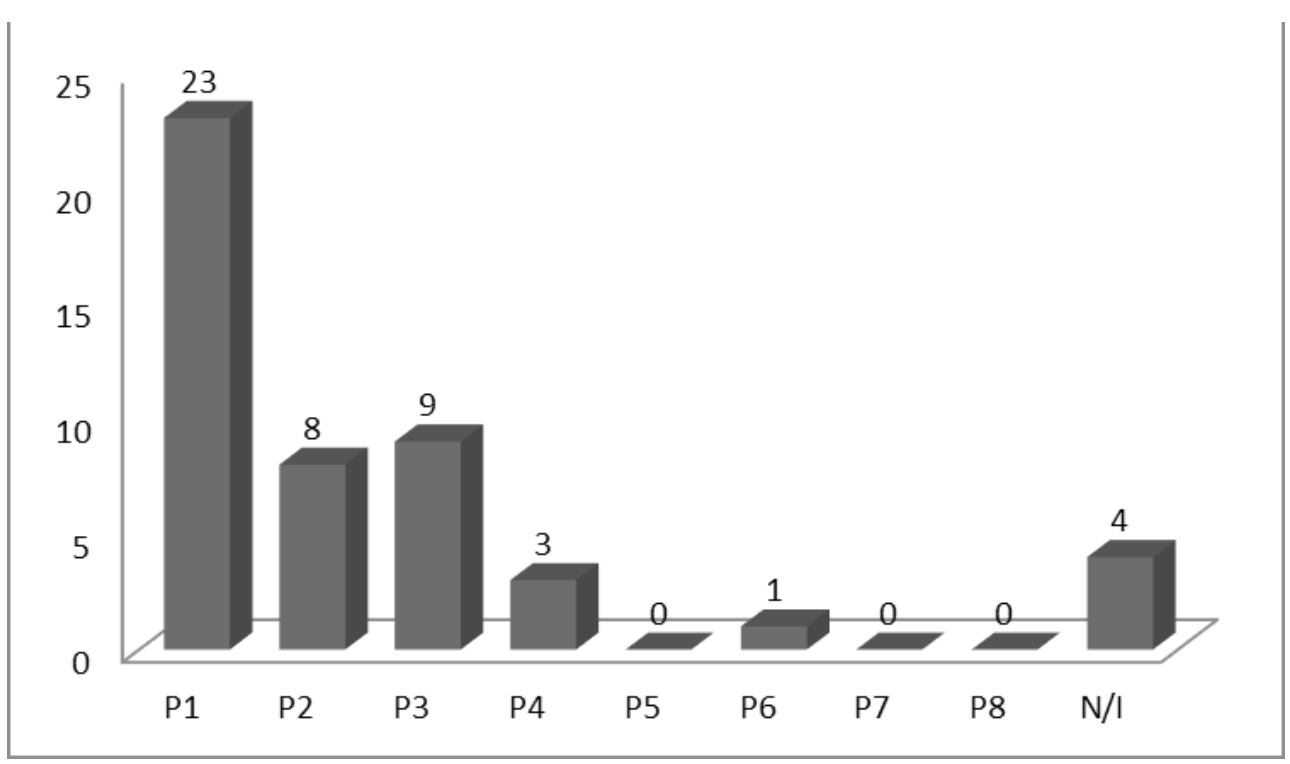

FONTE: Elaboração própria, 2018.

A evasão ocorrida no início do curso está frequentemente associada a fatores pessoais relacionados com a escolha inicial, dificuldades do discente em se adaptar às imposições dos professores e diferenças entre o ensino médio e o superior. No caso em que o discente evade por volta do quarto e do sexto semestres, normalmente está associada às incertezas sobre a profissão e, no final do curso, as questões são mais objetivas e comumente estão relacionadas ao mercado de trabalho e à busca por emprego ${ }^{17}$.

A Tabela 3 apresenta os fatores apontados pelos discentes ao serem questionados sobre a principal causa de sua evasão.

\section{Evasão associada a fatores pessoais}

A parcela de discentes que acreditam que os principais fatores que os levaram a evadir do curso foram pessoais atingiu o percentual de $78,2 \%$. Entre esses fatores, foram citados a não identificação com o curso, o interesse por outro campo profissional, a escassez de recursos financeiros, o desconhecimento a respeito do curso, a falta de habilidades para o estudo e problemas relacionados à saúde.

Estudos apontam a relevância dos fatores pessoais do discente na evasão universitária, visto que nesse período, ele está cercado por incertezas, ansiedades e dúvidas que permeiam a difícil situação de optar por um curso superior, que podem ser agravadas pela transmissão de uma visão negativa da profissão e do mercado de trabalho pela sociedade $^{18,19}$.
Tabela 3 - Fatores determinantes na evasão de discentes do curso

\begin{tabular}{|c|c|c|}
\hline $\begin{array}{l}\text { PRINCIPAIS FATORES DE } \\
\text { EVASÃO }\end{array}$ & $N=46$ & $\%$ \\
\hline Falta de identificação com o curso & 12 & $26,1 \%$ \\
\hline $\begin{array}{l}\text { Interesse por outro campo } \\
\text { profissional }\end{array}$ & 07 & $15,2 \%$ \\
\hline Escassez de recursos financeiros & 06 & $13 \%$ \\
\hline Desconhecimento a respeito do curso & 04 & $8,7 \%$ \\
\hline Mercado de trabalho insatisfatório & 04 & $8,7 \%$ \\
\hline Falta de habilidades para o estudo & 03 & $6,5 \%$ \\
\hline Problemas referentes a docentes & 02 & $4,3 \%$ \\
\hline Problemas relacionados à saúde & 02 & $4,3 \%$ \\
\hline Excesso de carga horária & 01 & $2,2 \%$ \\
\hline Conjuntura econômica desfavorável & 01 & $2,2 \%$ \\
\hline Aprovação em outra instituição & 01 & $2,2 \%$ \\
\hline Mudança de estado & 01 & $2,2 \%$ \\
\hline Desorganização institucional & 01 & $2,2 \%$ \\
\hline Auxílios estudantis insatisfatórios & 01 & $2,2 \%$ \\
\hline
\end{tabular}

FONTE: Elaboração própria, 2018. 
Os relatos a seguir demonstram a influência da falta de identificação com o curso no processo de evasão, que pode se dever ao desconhecimento sobre a profissão.

\begin{abstract}
No meu caso a razão de ter deixado o curso foi pessoal (não me identifiquei). Não fiquei muito tempo no curso, sendo assim não conheci muitos professores, mas os poucos que conheci foram ótimos (P12).
\end{abstract}

Saí apenas por ter outra meta, mas acredito que há déficit na disseminação da informação a respeito do curso dentro e fora da universidade, o que leva alguns estudantes, sejam universitários ou não, a começarem TO apenas por certa "curiosidade” (P37).

Outro fator que chamou a atenção foi a escassez de recursos financeiros, apontada por seis participantes como determinante para o abandono do curso, o que pode indicar a insuficiência das ações de assistência e permanência estudantil oferecidas pela UFPB e/ou a vulnerabilidade socioeconômica das famílias desses estudantes. Esta última se verifica parcialmente pelo fato de que, dos $32,6 \%$ dos respondentes que exerceram atividades de trabalho durante o período em que cursaram Terapia Ocupacional, $40 \%$ consideraram a necessidade de trabalhar o fator determinante de sua evasão.

\section{Evasão associada a fatores internos à UFPB}

O índice de discentes que relacionaram sua saída principalmente a fatores internos à instituição foi de $10,9 \%$. As principais causas apontadas foram os problemas referentes a docentes, o excesso de carga horária, a desorganização institucional e os auxílios estudantis insatisfatórios.

A desorganização da instituição, a falta de comprometimento por parte de alguns docentes, o curso não é muito valorizado na área da saúde da UFPB, os próprios discentes desconhecem do que se trata a Terapia Ocupacional antes de ingressarem devido à pequena repercussão, infelizmente boa parte da sociedade não conhece (P44).

Tenho TDAH, e na época, além de trabalhar eu não consegui acompanhar o ritmo do curso. Embora o curso me encante até hoje, a didática de certos professores era perturbadora (P43).

Falta também auxílio. Tem muita gente que sai (como eu) porque às vezes não tem nem a passagem para ir assistir aula, ou o professor pede carimbo, e meus colegas me doaram um, pois era exigido nos cenários. O curso é integral, mas só tive direito a dois dias de RU, os outros eu ficava com fome, ou dividia almoço com alguém. Não é porque somos alunos, que não passamos dificuldades (P7).

É importante ressaltar que a quase totalidade dos relatos sobre o corpo docente foi de discentes que abandonaram o curso em seus períodos iniciais, nos quais a maioria dos docentes são de outros departamentos da universidade e ministram disciplinas básicas, principalmente das áreas biológicas e biomédicas. Isso pode indicar a necessidade de maior articulação da coordenação do curso de Terapia Ocupacional com esses departamentos e professores, para esclarecer sobre a profissão e construir estratégias conjuntas para melhor aproveitamento dos processos de ensino e aprendizagem pelos discentes.

Dentre os evadidos respondentes, 21,73\% afirmaram ter procurado auxílios assistenciais e de permanência na universidade; destes, $70 \%$ os apontaram como satisfatórios ou parcialmente satisfatórios e, 30\%, como insatisfatórios. Os auxílios institucionais mais citados foram: auxílio creche, auxílio alimentação, auxílio moradia e auxílio transporte. Além disso, os discentes apontaram como um dos auxílios fornecidos a escuta realizada por docentes do Departamento de Terapia Ocupacional.

\section{Evasão associada a fatores externos à UFPB}

As atribuições de evasão a fatores externos à instituição, como o mercado de trabalho insatisfatório e conjuntura econômica desfavorável, alcançaram o percentual de $10,9 \%$.

Mercado de Trabalho, retorno financeiro e a falta de valorização do curso (P10).

Acredito que faltam reconhecimento, emprego e melhor salário (P20).

A apreensão dos discentes evadidos sobre o mercado de trabalho pode se dever ao fato da Terapia Ocupacional ser ainda recente no estado da Paraíba e estar em processo inicial de reconhecimento e valorização, o que se soma à situação dos trabalhadores de saúde, que possuem sobrecarga de tensão e altos níveis de estresse e ansiedade, ocasionados por longas jornadas, vários vínculos empregatícios, baixos salários e precarização das relações trabalhistas ${ }^{20,21}$.

Outros possíveis fatores que permeiam a insegurança do discente em relação à profissão escolhida dizem respeito à opção por uma carreira não tradicional e às discriminações dela decorrentes:

É notório que questões relacionadas a preconceitos 
que permeiam historicamente o cenário das profissões parecem marcar ainda hoje a trajetória dos cursos e dos profissionais no Brasil. Trabalhadores que não atuam em áreas consideradas e seguidas pelas classes dominantes no Brasil desde o período colonial, tais como medicina, direito, engenharias e outras, parecem sofrer ainda na contemporaneidade com discriminações que resultam em baixos salários, baixa autoestima dos profissionais, e na exclusão dessas atividades do rol das profissões vistas como "importantes" para a sociedade (p.400-1) $)^{22}$.

\section{Soluções e estratégias apontadas pelos discentes evadidos para a redução da evasão}

Contradizendo em parte o fato de que a maioria da evasão do curso se deveu a fatores pessoais, $76,1 \%$ afirmaram acreditar que haveria alguma solução que os mantivesse no curso, sendo as possibilidades mais citadas: melhoria dos auxílios estudantis, por $45,4 \%$ desses discentes; melhor capacitação do corpo docente, por $18,6 \%$; e redução da carga horária, por $18 \%$. Outras soluções pontuadas pelos discentes foram o reconhecimento da profissão $(9 \%)$ e o apoio cognitivo e psicológico (9\%).

Essa contradição pode indicar que parte desses estudantes, embora tenham colocado fatores pessoais como os principais determinantes de sua evasão, acreditem que poderiam ter prosseguido com o curso se a instituição lhes oferecesse melhores condições de permanência, visto que quase metade dos discentes apontaram a melhoria dos auxílios estudantis como uma questão que poderia ter evitado o abandono do curso.

No que diz respeito às condições de assistência e permanência estudantil, os participantes apontaram tanto o seu desconhecimento sobre as possibilidades de auxílios durante sua passagem pela universidade quanto a insuficiência dos auxílios prestados pela Pró-Reitoria de Assistência e Promoção ao Estudante (PRAPE), responsável por acompanhar e avaliar o desenvolvimento do Programa Nacional de Assistência Estudantil (PNAES) na UFPB.

O PNAES é responsável pelo apoio à permanência de discentes de baixa renda matriculados em cursos de graduação presenciais em instituições federais e tem como principal objetivo reduzir as desigualdades internas a fim de melhorar o desempenho acadêmico e diminuir, consequentemente, a evasão estudantil. O Programa propõe assistência estudantil à alimentação, moradia, transporte, saúde, inclusão digital, cultura, esporte, creche e apoio pedagógico e as ações são executadas pelas próprias instituições de ensino ${ }^{23}$.

Se pelo menos eu tivesse o auxilio creche, teria como assistir as aulas sem me preocupar com a minha filha (P2).

Depois que desisti fiquei sabendo de alguns auxílios, tipo o berçário ou escolinha na instituição no periodo em que eu estivesse em aula, mas teria um processo para conseguir a vaga (P4).

Tipo tentar uma bolsa ou algo do tipo, como uma ajuda dos professores na questão de ser flexivel com os horários, pois só deixei o curso porque precisava trabalhar (P7).

Diminuir a carga horária, pois muitos que estudam precisam trabalhar e como o curso era o dia todo, não tinha a mínima possibilidade, então ou você estuda ou trabalha (P10).

A respeito de estratégias para a redução da evasão no curso, os participantes apontaram: melhor divulgação da profissão para a sociedade $(43,4 \%)$, diminuição de carga horária $(10,8 \%)$, aumento e melhoria de auxílios estudantis $(10,8 \%)$, ciação de uma rede de apoio aos estudantes $(8,6 \%)$ e melhorias estruturais na UFPB (4,3\%).

Melhor esclarecimento para os calouros acerca da atuação do profissional, bem como, melhor relacionamento da instituição formadora em colaboração com as representações sindicais a fim de pressionar junto a órgãos e empresas para ampliação do mercado de trabalho (público ou privado) no estado da Paraíba (P2).

Melhoria das politicas/programas de assistência estudantil na universidade. Maior carga horária prática nas disciplinas específicas do curso nos primeiros períodos. Flexibilidade dos professores que são de outros departamentos e ministram disciplinas para o curso. Uma rede de apoio aos estudantes, para o aluno ter um espaço que possa ser ouvido, possa conversar, ouvir outras perspectivas (P33).

Complicado responder essa questão, os motivos que me levaram a abandonar o curso envolveram também questões pessoais, a maioria das pessoas que conheço que desistiu do curso foi por achar que o curso seria do jeito $A$ e foi do jeito $B$ (mesmo pesquisando na net você só entende realmente o que é o curso quando começa e estudar), a falta de mercado de trabalho e a remuneração baixa desestimulam os alunos e fora que a maioria não tinha TO como primeira opção, logo fica bastante complicado encontrar estratégias para evitar a evasão do curso, quando ao meu ver, o problema é mais externo do que do próprio curso (P22).

Outra estratégia possível para diminuição da evasão é o acompanhamento vocacional no período de iniciação 
do curso, a fim de motivar e preparar os discentes para a experiência universitária. Além disso, existe a necessidade de reformulação dos projetos pedagógicos dos cursos, visando transformar a vivência universitária dos discentes na mais positiva possível. O acompanhamento vocacional e a melhor divulgação das profissões devem se dar, também, anteriormente ao ingresso na universidade, dada a expressiva parcela de estudantes que não realizam sua escolha profissional com a devida reflexão e condições para tal, o que se traduz, no âmbito deste estudo, na falta de identificação com o curso como a causa mais citada pelos estudantes evadidos do curso de Terapia Ocupacional da UFPB.

Mesmo que $82,6 \%$ dos estudantes evadidos do referido curso tenham permanecido no ensino superior, a maioria deles $(41,3 \%)$ na área da saúde, configurando um processo de mobilidade estudantil ${ }^{24}$, devem-se desenvolver estratégias de acompanhamento vocacional antes do ingresso na universidade. Se realizadas durante o ensino fundamental e médio, tais estratégias podem qualificar o percurso desses estudantes, levando-os a decisões mais acertadas e que acarretem menos prejuízos pessoais e para o sistema educacional público brasileiro.

\section{CONSIDERAÇÕES FINAIS}

Esse estudo identificou os principais fatores relacionados à evasão dos discentes do curso de Terapia

\section{REFERÊNCIAS:}

1. ANDIFES/ABRUEM/SESu/MEC. Comissão Especial de Estudos sobre Evasão nas Universidades Públicas Brasileiras. Diplomação, Retenção e Evasão nos Cursos de Graduação em Instituições de Ensino Superior Públicas. Outubro 1996. Disponível em: http://www.andifes.org.br/wp-content/ files_flutter/Diplomacao_Retencao_Evasao_Graduacao_em IES_Publicas-1996.pdf.

2. Lobo RL, Motejunas PR, Hipólito O, Lobo MB. A evasão no ensino superior brasileiro. Cad Pesq Fund Carlos Chagas. 2007;37(132):641-59. Disponível em: http://www. institutolobo.org.br/imagens/pdf/artigos/art_045.pdf.

3. INEP-MEC/DEED. Resumo técnico: censo da educação superior de 2009. Disponível em: http://download.inep.gov. br/download/superior/censo/2009/resumo_tecnico_2009.pdf.

4. Lobo R. A evasão no ensino superior brasileiro - novos dados. Instituições, sistemas e indicadores da educação superior, da ciência e da tecnologia no Brasil e no mundo. Estadão, 17 out. 2017. Disponível em: http://educacao.estadao.com.br/blogs/ roberto-lobo/497-2/
Ocupacional da UFPB e trouxe subsídios para a construção de estratégias de melhoria do curso e de redução da evasão, além de ter fornecido embasamento para a problematização e enfrentamento de questões institucionais relacionadas a esse fenômeno. Acredita-se que o mapeamento desses fatores e a construção de estratégias para a redução da evasão poderão trazer rebatimentos para a consolidação do curso na UFPB e no estado da Paraíba, que está em seu estágio inicial e teve seus primeiros terapeutas ocupacionais formados no ano de 2014.

Identificou-se que a evasão do curso de Terapia Ocupacional da UFPB é multifatorial, visto que os discentes participantes apontaram fatores pessoais e fatores internos e externos à instituição como determinantes para sua decisão de abandono do curso.

Considerando que a maioria dos fatores de evasão são pessoais, sendo o principal deles a não identificação com o curso, e que a divulgação da Terapia Ocupacional aparece como a estratégia mais citada para a redução da evasão, as ações para minimização desse fenômeno devem priorizar o investimento no melhor conhecimento da profissão pela sociedade, estudantes do ensino fundamental e médio, discentes recém-chegados no curso, demais cursos da UFPB e sistemas estaduais e locais de saúde, educação, assistência social e cultura. Além disto, devem ser desenvolvidas ações de luta pela melhoria da estrutura e do funcionamento do curso e da UFPB e das condições de assistência e permanência estudantil.

5. Daniel C. MEC divulga o Censo da Educação Superior de 2016. Eu estudante. Correio Braziliense, 31 ago. 2017. Disponível em: https://www.correiobraziliense.com.br/app/ noticia/eu-estudante/ensino_ensinosuperior/2017/08/31/ ensino_ensinosuperior_interna,622359/mec-divulga-o-censoda-educacao-superior-de-2016.shtml

6. PROGRAD/FORPLAD/UNIFESP. Dados comparados sobre evasão nos cursos de graduação em Universidades Federais - ano referência 2014. Disponível em: http://www.unifesp. br/reitoria/prograd/pro-reitoria-de-graduacao/informacoesinstitucionais/graduacao-em-numeros?download=600:evas ao-2014.

7. Flick U. Introdução à pesquisa qualitativa. Porto Alegre: Artmed, 2009.

8. Predanov CC, Freitas EC. Metodologia do trabalho científico: métodos e técnicas da pesquisa e do trabalho acadêmico. $2^{\mathrm{a}}$ ed. Novo Hamburgo: Universidade FEEVALE; 2013. Disponível em: http://www.feevale.br/Comum/midias/8807f05a-14d04d5b-blad-1538f3aef538/E-book\%20Metodologia\%20do\%20 Trabalho\%20Cientifico.pdf. 
9. Brasil. Resolução n.466, de 12 de dezembro de 2012. Aprova normas regulamentadoras de pesquisas envolvendo seres humanos. Diário Oficial da União, 2013 jun. 13. Seção 1, p. 59. Disponível em: http://bvsms.saude.gov.br/bvs/ saudelegis/cns/2013/res0466_12_12_2012.html.

10. Gibbs G. Análise de dados qualitativos. Porto Alegre: Artmed; 2009.

11. Mosquera JJM, Stobaus CD. Vida adulta: visão existencial e subsídios para teorização. Educação (Porto Alegre). 1982;5:94-112.

12. FGV Social. Centro de Políticas Sociais. Qual a faixa de renda familiar das classes? [citado 24 maio 2018]. Disponível em: http://cps.fgv.br/qual-faixa-de-rendafamiliar-das-classes.

13. Matos M, Féres CT, Jablonksi B. Adolescência e relações amorosas: um estudo sobre jovens das camadas populares cariocas. Interação Psicologia. 2005;9(1):21-33. doi: http:// dx.doi.org/10.5380/psi.v9i1.3283.

14. Prates AAP, Barbosa MLO. A expansão e as possibilidades de democratização do ensino superior no brasil. Cad CRH. 2015;28(74):327-40. doi: http://dx.doi.org/10.1590/S010349792015000200006 .

15. Brasil. Ministério da Educação. Secretaria de Educação Superior. Diretoria de Desenvolvimento das Instituições Federais de Ensino Superior. Reuni 2008: relatório de primeiro ano. 30 out 2009. Disponível em: http://portal.mec.gov.br/index.php?option=com docman $\&$ view $=$ download $\&$ alias $=2069$-reuni-relatoriopdf\&Itemid $=30192$.

16. Gilioli RSP. Evasão em instituições federais de ensino superior no Brasil: expansão da rede, SISU e desafios. Brasília: Consultoria Legislativa, Câmara dos Deputados;
2016. p.36-48. Disponível em: http://www2.camara.leg. br/atividade-legislativa/estudos-e-notas-tecnicas/areasda-conle/tema11/2016_7371_evasao-em-instituicoes-deensino-superior_renato-gilioli

17. Harnick S. Má escolha e a causa de evasão. Folha de São Paulo, Caderno Educação, 18 out. 2005. Disponível em: http://www.ufac.br/forum/ipb/index.php?showtopic=103 $\&$ pid $=665 \&$ st $=0 \& \#$ entry 665 .

18. Augustin C. Dinâmica das vagas. UERJ [citado 15 jun. 2008]. Disponível em: http://www2.uerj.br/ niesc/datauerj/ estudos/Dinamica_texto.htm.

19. Tigrinho LMV. Evasão escolar nas instituições de ensino superior. Rev Gest Univ. 2008;173:1-14. Disponível em http://www.gestaouniversitaria.com.br/artigos/evasaoescolar-nas-instituicoes-de-ensino-superior.

20. Ferrari R, França FM, Magalhães J. Avaliação da síndrome de burnout em profissionais de saúde. Rev Eletrônica Gestão Saúde. 2012;3(3):868-83. doi: http://dx.doi.org/10.18673/ gs.v3i3.23066.

21. Souza WC, Silva AMM. A influência de fatores de personalidade e de organização do trabalho no burnout em profissionais de saúde. Estud Psicol. 2002;19(1):37-48. http://dx.doi.org/10.1590/S0103-166X2002000100004.

22. Silva FIC, Rodrigues JP, Brito AKA, França NM. Evasão escolar no curso de educação física da Universidade Federal do Piauí. Avaliação Rev Avaliação Educ Superior. 2012;17(2):394-404. http://dx.doi.org/10.1590/S141440772012000200006 .

23. Brasil. Controladoria Geral da União. Relatório consolidado PNAES. Brasília, DF; 2017.

24. Ristoff DI. Universidade em foco: reflexões sobre a educação superior. Florianópolis: Editora Insular; 1999. 